\title{
Identifikasi Kawasan Batu Termanu sebagai Salah Satu Destinasi Wisata di Kabupaten Rote Ndao
}

\author{
Linda Marlince Taka ${ }^{1}$ \\ Fatrisia Yulianie ${ }^{2}$
Program Studi Usaha Perjalanan Wisata Akademi Pariwisata Kupang
Jln. Karya Kencana Kelapa Lima Kupang \\ Email: lindataka27@yahoo.com/yulianie-f@gmail.com
}

\begin{abstract}
Tourism activities should pay attention to several principles of management, besides the fulfillment of the tourists' needs, the other thing to be noted is the surrounding communities without damaging the natural environment and its cultural and having a positive impact on the welfare of the local community so that it will create balance between tourism and the community. Batu Termanu region has tourism potential such as marine tourism, culture and history as a tourist attraction, but it has not developed properly. This study aims to determine the potential of Batu Termanu Region as a tourist destination area and to define the right strategy of tourism development here. Data analysis method used was SWOT analysis. The result of this study showed that Batu Termanu Region has the potential of natural, culture, history appeal and kinship community, but it was not fully supported yet by the facilities, infrastructure, transport and friendliness that support tourist activities. The right strategies in developing this area were to build all of the facilities and good infrastructure, promotion, making travel packages, to involve the community in the development process.
\end{abstract}

Keywords: tourism potential, Batu Termanu region, tourism development.

\section{Pendahuluan}

Pembangunan dan pengembangan pariwisata harus didasarkan pada kearifan lokal dan special local interest yang merefleksikan keunikan peninggalan budaya dan keunikan lingkungan; preservasi, proteksi dan peningkatan kualitas sumber daya; pengembangan atraksi wisata yang mengakar pada khasanah budaya local, pelayanan berbasis keunikan budaya dan lingkungan lokal; memberikan dukungan dan legitimasi pada pembangunan dan pengembangan pariwisata yang terbukti memberikan manfaat positif tetapi mengendalikan atau menghentikan aktivitas pariwisata jika melewati ambang batas. 
Tabel 1 :

Jumlah Kunjungan Wisatawan Asing dan Lokal di Nusa Tenggara Timur

\begin{tabular}{|c|c|c|c|c|}
\hline \multirow{2}{*}{ No } & \multirow{2}{*}{ Kabupaten } & \multicolumn{2}{|c|}{ Wisatawan } & \multirow{2}{*}{ Jumlah } \\
\hline & & Asing & Lokal & \\
\hline 1 & Sumba Barat & 597 & 3.952 & 4.549 \\
\hline 2 & Sumba Timur & 522 & 9.580 & 10.102 \\
\hline 3 & Kab.Kupang & - & - & - \\
\hline 4 & TTS & 34 & 7.554 & 7.588 \\
\hline 5 & TTU & 110 & 3.697 & 3.807 \\
\hline 6 & Belu & 2.423 & 17.393 & 19.816 \\
\hline 7 & Alor & 56 & 2.716 & 2.772 \\
\hline 8 & Lembata & 56 & 1.511 & 1.567 \\
\hline 9 & Flores Timur & 223 & 15.074 & 15.297 \\
\hline 10 & Sikka & 3.970 & 18.712 & 22.682 \\
\hline 11 & Ende & 7.583 & 20.130 & 27.713 \\
\hline 12 & Ngada & 2.980 & 3.860 & 6.840 \\
\hline 13 & Manggarai & 3.719 & 10.711 & 14.430 \\
\hline 14 & Rote Ndao & 538 & 409 & 947 \\
\hline 15 & Mabar & 15.722 & 15.296 & 31.018 \\
\hline 16 & Sumteng & - & - & - \\
\hline 17 & SBD & 157 & 108 & 265 \\
\hline 18 & Nagakeo & 32 & 5.880 & 5.912 \\
\hline 19 & Matim & 134 & 2.091 & 2.225 \\
\hline 20 & Sabu & 9 & 145 & 154 \\
\hline 21 & Malaka & - & - & - \\
\hline \multirow[t]{2}{*}{22} & Kota kupang & 6.242 & 179.839 & 186.081 \\
\hline & Jumlah & 45.107 & 318.658 & 363.765 \\
\hline
\end{tabular}

Sumber : BPS Propinsi NTT 2013

Dari data tabel diatas yang menunjukan jumlah kunjungan wisatawan pada tahun 2013 Kabupaten Rote Ndao bahwa kunjungan wisatawan asing maupun lokal masih rendah apabila dibandingan dengan Kabupaten lain seperti terlihat pada Kabupaten Manggarai yang jumlah kunjungan wisatawannya sangat tinggi.

Objek utama dalam penelitian ini adalah Kawasan Batu Termanu yang terletak di Kelurahan Onatali, Kecamatan Rote Tengah, Kabupaten Rote Ndao. Kawasan ini termasuk unik dan menarik karena memiliki daya tarik pantai, alam bawah laut, adat istiadat masyarakat sekitar dan tentunya yang terkenal yaitu dua buah batu besar yang sangat legenda di masyarakat Rote bahkan masyarakat Nusa Tenggara Timur pada umumnya.

Kawasan Batu Termanu juga memiliki keunikan dimana seluruh anggota masyarakat memiliki keterkaitan kerabat satu dengan lainnya. Sistem kekerabatan yang erat masih terjaga oleh sebab seluruh anggota masih teguh memilihara adat istiadat sebagai penjaga hubungan tersebut. Pola kekerabatan inilah yang dijadikan dasar hubungan kemasyarakat termasuk kepada pendatang sehingga penduduk desa menganggap pendatang seperti saudara yang pulang kampung. Hal ini dimungkin akan mengingat sebagian besar angkatan kerja desa perg i merantau di kota besar. Keterbukaan yang ditampilkan masyarakat tersebut merupakan prasyarat dasar pelayanan prima (Zoh dan Indrayana : 2008 ).

Faktor diberlakukannya otonomi daerah tidak bisa di sangkal memiliki peran yang besar, ditambah lagi dengan adanya arahan kebijakan yang memang menekankan untuk mengembangkan sektor pariwisata sebagai 
sektor prioritas. Kedua faktor ini didukung pula dengan kondisi alam Batu Termanu yang memang potensial untuk pengembangan pariwisata, memacu pemerintah Kabupaten Rote Ndao untuk mengembangkan kawasan ini yang dipandu dengan suatu rencana yang strategis (Dinas Pariwisata dan Kebudayaan Rote Ndao :2005).

\section{Pembahasan}

Pariwisata adalah kegiatan melakukan perjalanan dengan tujuan mendapatkan kenikmatan, mencari kepuasan, mengetahui sesuatu, memperbaiki kesehatan, menikmati olah raga atau istirahat, menunaikan tugas dan lain-lain (Spillane :1994).

Kawasan wisata dapat dibagi menjadi dua menurut Antari (dalam Septhi 2001) yaitu:

Kawasan pariwisata murni yaitu suatu areal yang secara khusus disediakan untuk menampung berbagai kegiatan pariwisata, dilengkapi dengan berbagai saran penunjang untuk memudahkan bagi kegiatan pariwisata, dimana pengelolaannya ditangani oleh suatu badan baik pemerintah maupun swasta atau kerjasama pemerintah dengan swasta.

Kawasan pariwisata terbuka yaitu kawasan yang bobotnya dipergunakan untuk pengembangan pariwisata di kawasan pariwisata tersebut, kegiatan lainnya dari masyarakat umum seperti pertanian, perkebunan, dan lain sebagainya masih terbuka, yang diatur dan ditata agar mendukung pengembangan pariwisata.

Jenis Pariwisata menurut Spillane (1994) adalah sebagai berikut :

1. Pariwisata untuk menikmati perjalanan (Pleasure Tourism)

2. Pariwisata untuk rekreasi (Recreation Tourism)

3. Pariwisata untuk kebudayaan (Culture Tourism)

4. Pariwisata untuk urusan usaha dagang besar (Business Touris )

5. Pariwisata untuk olah raga (Sports Touris)

6. Pariwisata untuk konvensi (Convention Tourism)

7. Industri Pariwisata

Menurut Spillane (1994) ada lima unsur industri pariwisata yang sangat penting sebagai berkut : Attactions (daya tarik)

Attractions dapat digolongkan menjadi site atractions dan event attractions. Site attractions merupakan daya tarik fisik yang permanen dengan lokasi yang tetap. Sedangkan event attractions adalah atraksi yang berlangusng sementara dan lokasinya dapat diubah atau dipindah dengan mudah.

Facilities (fasilitas)

Fasilitas cenderung berorientasi pada daya tarik di suatu lokasi karena fasilitas harus terletak dekat dengan pasarnya. Selama tinggal di tempat tujuan wisata, wisatawan memerlukan tidur, makan dan minum. Oleh karena itu sangat dibutuhkan fasilitas penginapan.

Infrastructure (infrastruktur)

Daya tarik dan fasilitas tidak dapat dicapai dengan mudah kalau belum ada infrastruktur dasar. Infrastruktur termasuk semua konstruksi dibawah dan diatas tanah dari suatu wilayah atau daerah, bagian penting dari infrastruktur pariwisata.

Transportations (transportasi)

Dalam pariwisata, kemajuan dunia transportasi atau pengangkutan sangat dibutuhkan karena sangat menentukan jarak dan waktu dalam suatu perjalanan pariwisata.

Hospitality (keramahtamahan)

Situasi yang kurang aman mengenai makanan, air, atau perlindungan memungkinkan orang menghindari berkunjung ke suatu lokasi. Maka kebutuhan dasar akan keamanan dan perlindungan harus disediakan dan juga keuletan serta keramahtamahan tenaga kerja wisata perlu dipertimbangkan supaya wisatawan merasa aman dan nyaman selama perjalanan wisata.

Menurut Yoeti (2008), pariwisata memiliki enam ciri antara lain :

Service Industri

Pengertian-pengertian yang terkandung dalam services industry antara lain : penyediaan jasa-jasa pariwisata (tourist supply) berlaku pula hukum ekonomi dan tidak terlepas dari permasalahan permintaan (demand) dan penawaran (supply). Penawaran (supply) dalam industri pariwisata tidak tersedia bebas akan tetapi diperlukan pengolahan dan pengorbanan (biaya) untuk memperolehnya.

Labor Intensive 
Yang dimaksud dengan labor intensive pariwisata sebagai suatu industri adalah banyak menyerap tenaga kerja. Dalam suatu penelitian mengatakan beberapa persen dari belanja wisatawan pada suatu daerah wisata digunakan untuk membayar upah dan gaji (wages and salaries).

Capital Intensive

Industri pariwisata sebagai capital intensive adalah untuk membangun sarana dan prasarana industri pariwisata diperlukan modal yang besar untuk investasi, akan tetapi dilain pihak pengembalian modal yang diinvestasikan itu relatif lama dibandingkan dengan industri manufaktur lainnya.

Sensitive

Industri pariwisata sangat peka terhadap keamanan (security) dan kenyamanan (comfortably). Dalam melakukan perjalanan wisata tidak seorang pun wisatawan yang mau mengambil resiko dalam perjalanan yang dilakukan. Sebagai contoh ketika terjadi ledakan bom di Bali kunjungan wisatawan mancanegara ke Bai turun merosot hingga hotel, restoran dan toko cenderamata menutup usahanya

Seasonal

Industri pariwisata sangat dipengaruhi oleh musim, bila pada masa musim liburan (peak season) semua kapasitas akan terjual habis dan sebaliknya pada masa musim libur selesai (off-season) semua kapasitas terbengkalai (idle) karena sepi pengunjung.

Quick Yielding Industry

Dengan mengembangkan pariwisata sebagai suatu industri, devisa (foreign exchange) akan lebih cepat jika dibandingkan dengan kegiatan ekspor yang dilakukan secara konvensional. Devisa yang diperoleh langsung pada saat wisatawan melakukan perjalanan wisata, karena wisatawan harus membayar semua kebutuhannya mulai dari akomodasi hotel, makanan dan minuman, transportasi lokal, oleh-oleh atau cenderamata, hiburan city sightseeing dan tours. Semuanya dibayar dengan valuta asing yang tentunya ditukarkan di money changer atau bank.

\section{Konsep Daerah Tujuan Wisata}

Menurut Cooper (1995: 81) mengemukakan bahwa terdapat 4 (empat) komponen yang harus dimiliki oleh sebuah objek wisata, yaitu:

1. 1. Atraksi (Attraction), seperti alam yang menarik, kebudayaan daerah yang menawan dan seni pertunjukan.

2. Aksesibitas (accessibilities) seperti transportasi lokal dan adanya terminal.

3. Amenitas atau fasilitas (amenities) seperti tersedianya akomodasi, rumah makan, dan agen perjalanan.

4. Ancillary services yaitu organisasi kepariwisataan yang dibutuhkan untuk pelayanan wisata seperti destination marketing management organization, conventional and visitor bureau.

Suatu daerah tujuan wisata, agar menarik untuk dikunjungi oleh wisatawan potensia 1 dalam berbagai pasar, maka harus memiliki tiga syarat (Yoeti, 1996: 177) yaitu:

1. Daerah tersebut harus mempunyai apa yang disebut sebagai "something to see". Artiya di tempat tersebut harus ada objek wisata dan atraksi wisata yang berbeda dengan apa yang dimiliki oleh daerah lain ( segala sesuatu yang menarik untuk dilihat )

2. Daerah tersebut harus tersedia dengan apa yang disebut sebagai "something to do". Artinya di tempat tersebut setiap banyak yang dapat dilihat dan disaksikan, harus pula disediakan fasilitas rekreasi yang dapat membuat wisatawan betah tinggal lebih lama di tempat itu ( aktivitas yang dapat dilakukan ditempat tersebut ).

3. Daerah tersebut harus tersedia apa yang disebut sebagai "something to buy". Artinya di tempat tersebut harus tersedia fasilitas untuk berbelanja (shopping), terutama barang-barang souvenir dan kerajinan rakyat sebagai oleh-oleh untuk dibawa pulang ke tempat asal wisatawan ( segala sesuatu yang menarik / mempunyai ciri khas tersendiri untuk dibeli.

\section{Konsep Pengembangan Daerah Wisata}

Pengembangan (Poerwa Darminta, 2002 adalah suatu proses atau cara menjadikan sesuatu menjadi maju, baik, sempurna, dan berguna. Pengembangan diartikan sebagai proses atau perbuatan pengembangan dari belum ada, dari yang sudah ada menjadi lebih baik dan dari yang sudah baik menjadi lebih baik, demikian seterusnya.Tahapan pengembangan merupakan tahapan siklus evolusi yang terjadi dalam pengembangan pariwisata, sejak suatu daerah tujuan wisata baru ditemukan (discovery), kemudian berkembang dan pada akhirnya terjadi penurunan (decline).

Menurut Butler (dalam Pitana, 2005: 103) ada 7 fase pengembangan pariwisata atau siklus hidup pariwisata (Destination Area Lifecycle) yang membawa implikasi serta dampak yang berbeda, secara teoritis diantaranya: Fase exploration (eksplorasi/penemuan). Pada tahap ini terjadi kontak yang tinggi antara wisatawan dengan 
masyarakat lokal, karena wisatawan menggunakan fasilitas lokal yang tersedia. Fase involvement (keterlibatan). Dengan meningkatnya jumlah kunjungan, maka sebagian masyarakat lokal mulai menyediakan berbagai fasilitas yang memang khusus diperuntukan bagi wisatawan. Kontak antara wisatawan dengan masyarakat dengan masyarakat lokal masih tinggi, dan masyarakat mulai mengubah pola-pola sosial yang ada untuk merespon perubahan ekonomi yang terjadi. Disinilah mulainya suatu daerah menjadi suatu destinasi wisata, yang ditandai oleh mulai adanya promosi. Fase development (Pembangunan). Investasi dari luar mulai masuk, serta mulai munculnya pasar wisata secara sistematis. Daerah semakin terbuka secara fisik dan promosi semakin intensif, fasilitas lokal sudah tersisih atau digantikan oleh fasilitas yang benar-benar berstandar internasional, dan atraksi buatan sudah mulai dikembangkan, menambahkan atraksi yang asli alami. Berbagai barang dan jasa inpor termasuk tenaga kerja asing, untuk mendukung perkembangan pariwisata yang pesat. Fase consolidation (konsolidasi). Pariwisata sudah dominan dalam struktur ekonomi daerah, dan dominasi ekonomi ini dipegang oleh jaringan internasional atau major chains and franchises. Jumlah kunjungan wisatawan masih naik, tetapi pada tingkat yang lebih rendah. Pemasaran semakin gencar dan diperluas untuk mengisi fasilitas yang sudah dibangun. Fasilitas lama sudah mulai ditinggalkan. Fase stagnation (kestabilan). Kapasitas berbagai faktor sudah terlampaui ( diatas ) daya dukung, carrying capasity), sehingga menimbulkan masalah ekonomi, sosial dan lingkungan. Kalangan industri sudah mulai bekerja keras untuk memenuhi kapasitas dari fasilitas yang dimiliki, khususnya dengan mengharapkan repeater guest dan wisata konvensi/bisnis. Pada fase ini, atraksi buatan sudah mendominasi atraksi asli alami (baik budaya maupun alam), citra awal sudah mulai luntur, dan destinasi sudah tidak lagi populer. Fase decline (penurunan). Wisatawan sudah mulai beralih ke destinasi wisata baru atau pesaing, dan yang tinggal hanya 'sisa-sisa', khususnya wisatawan yang hanya berakhir pekan. Banyak fasilitas pariwisata sudah beralih atau dialihkan fungsinya untuk kegiatan non-pariwisata, sehingga destinasi semakin tidak menarik bagi wisatawan. Partisipasi lokal mungkin meningkat lagi, terkait dengan harga yang merosot turun dengan melemahnya pasar. Destinasi bisa berkembang menjadi destinasi kelas rendah atau secara total kehilangan jati diri sebagai destinasi wisata. Fase rejuvenation (Peremajaan). Perubahan secara dramatis bisa terjadi (sebagai hasil dari berbagai usaha dari berbagai pihak), menuju perbaikan atau peremajaan. Peremajaan ini bisa terjadi karena inovasi dan pengembangan produk baru, atau menggali atau memanfaatkan sumber daya alam dan budaya yang sebelumnya.

Penelitian ini terfokus pada identifikasi potensi wisata yang ada di Kawasan Batu Termanu Kecamatan Rote Tengah. metode penelitian yang digunakan adalah metode deskriptif kualitatif yang mendeskripsikan atau menggambarkan atau melukiskan fenomena atau hubungan antar fenomena yang diteliti dengan sistematis, faktual dan akurat. Variabel dalam penelitian ini adalah strategi pengembangan daerah tujuan wisata yang meliputi Daya tarik, Fasilitas, Infrastruktur, Transportasi, Keramahtamahan.

Penelitian ini dilaksanakan pada bulan Mei sampai Juli tahun 2015 yang bertempat di Kawasan Batu Termanu, Kelurahan Onatali Kecamatan Rote Tengah Kabupaten Rote Ndao, Propinsi Nusa Tenggara Timur.

Data diperoleh dengan melakukan wawancara kepada 5 informan dipilih berdasarkan latar belakang dan memiliki peran penting dalam menentukan kebijakan di daerah tersebut. Kemudian data dikumpulkan dan diolah atau diproses, selanjutnya dianalisis dengan menggunakan metode analisis SWOT.

\section{Daya Tarik}

Keberhasilan dari suatu daerah wisata salah satunya sangat ditentukan oleh adanya daya tarik yang ada dan dikembangkan secara maksimal. Berdasarkan hasil penelitian di Kawasan Batu Termanu diperoleh laporan dari Dinas Pariwisata Kabupaten Rote Ndao (tahun 2013) bahwa kawasan ini memiliki daya tarik yang indah seperti pantai yang indah, wisata alamnya, budaya dan seni ( tarian, alat musik, kerajian tangan, pakaian adat ), upacara adat, kuliner dan batu bersejarahnya yang memiliki cerita rakyat yang sudah turun temurun pada masyarakat sekitar kawasan dan Kabupaten Rote Ndao pada umumnya. 


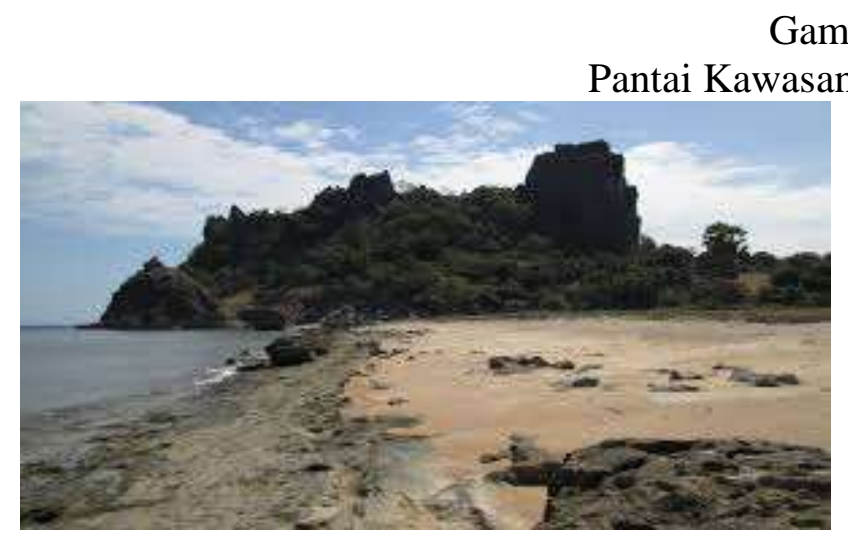

\section{Fasilitas}

Setelah melihat potensi daya tarik/atraksi yang ada di kawasan tersebut maka selanjutnya yaitu dengan melihat fasilitas yang nantinya akan mendukung pengembangan sehingga mempunyai nilai tambah kawasan Batu Termanu.

Tabel 5

Data Fasilitas di Kawasan Batu Termanu

\begin{tabular}{|l|l|l|}
\hline No & Fasilitas & Jumlah \\
\hline 1. & Penginapan / hotel & 1 buah \\
\hline 2. & Rumah makan & 1 buah \\
\hline 3. & Toko ( sovenir) & 2 buah \\
\hline 4. & Kios & 6 buah \\
\hline
\end{tabular}

Sumber: Dinas Pariwisata Rote Ndao ( 2014 )

Dari tabel di atas dapat dlihat bahwa fasilitas yang ada di kawasan Batu Termanu masih sangat minim belum memadai untuk mendukung pengembangan kawasan ini.

\section{Gambar 13}

Penginapan Tiberias

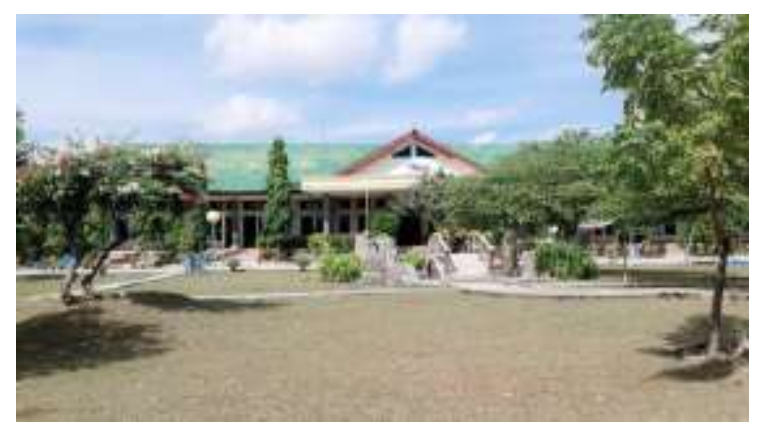

\section{Infrastruktur}

Menurut Spillane infrastruktur yang mendukung adanya suatu pengembangan yaitu sistem pengairan, jaringan komunikasi, fasilitas kesehatan, sumber listrik, air bersih, serta jalan .sedangkan kondisi infrastruktur dalam kawasan belum cukup mendukung untuk pengembangan Kawasan Batu Termanu, dengan kondisi jalan yang masih berupa jalan tanah, fasilitas kesehatan berupa alat-lat medis dan tenaga kesehatan yang masih kurang. 
Gambar 14

Kondisi jalan di dalam kawasan Batu Termanu

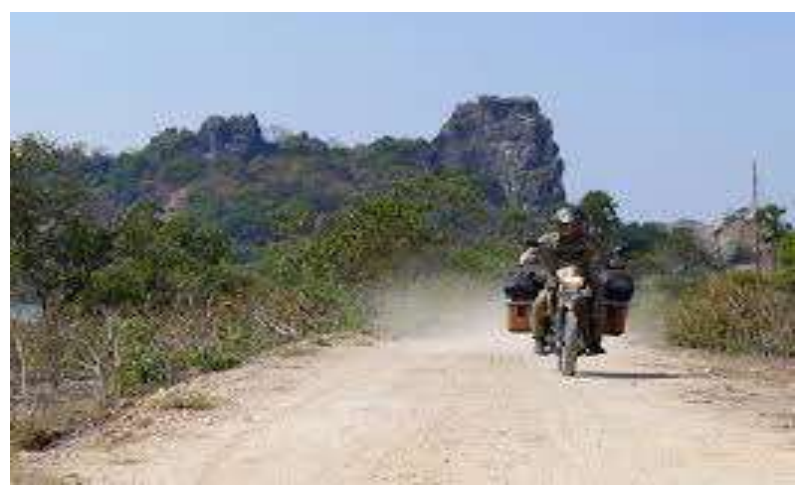

\section{Transportasi}

Tabel 6

Data Transportasi dari Kota Kupang menuju Kabupaten Rote Ndao:

\begin{tabular}{|l|l|l|}
\hline Jenis transportasi & $\begin{array}{l}\text { Jml rute/ } \\
\text { week }\end{array}$ & Harga/orang \\
\hline $\begin{array}{l}\text { Pesawat Udara } \\
\text { Wings Air }\end{array}$ & $3 \mathrm{x}$ & Rp. 400.000 \\
\hline $\begin{array}{l}\text { Kapal Expres } \\
\text { Bahari }\end{array}$ & $7 \mathrm{x}$ & $\begin{array}{l}\text { Rp. 180.000 } \\
- \text { Rp. } \\
285.000\end{array}$ \\
\hline $\begin{array}{l}\text { Kapal } \\
\text { penumpang } \\
\text { ASDP }\end{array}$ & $7 \mathrm{x}$ & Rp. 56.000 \\
\hline
\end{tabular}

Sumber : Dinas Pariwisata Rote Ndao (2015)

Dari tabel di atas menunjukan bahwa transportasi ke Kabupaten Rote Ndao dari Kota Kupang sudah sangat baik dengan harga tiket per penumpang yang relatif terjangkau dengan jumlah rute yang juga sudah memenuhi kebutuhan masyarakat.

\section{Gambar 17}

Kondisi Pelabuhan Ba'a

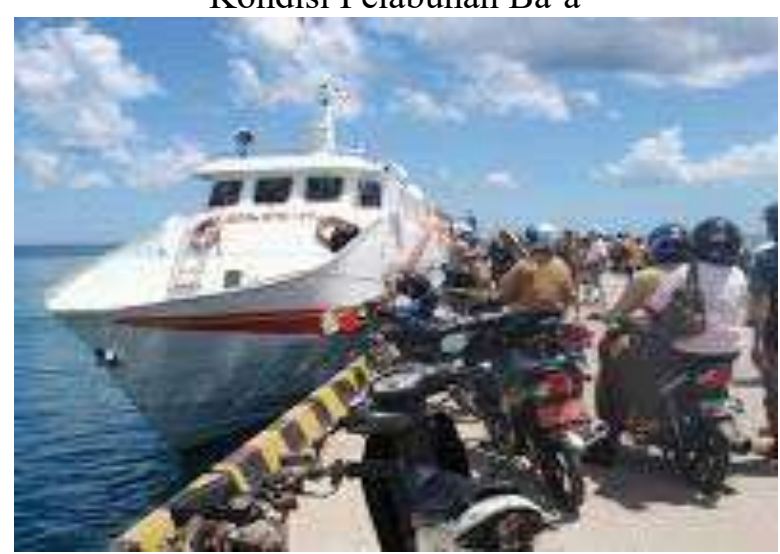

\section{Keramahtamahan}

Keramahtamahan disini yang dimaksudkan yaitu mengenai rasa aman dan nyaman (perlindungan) yang diberikan baik dari pemerintah,organisasi desa (pengelola kawasan), aparat kepolisian, tenaga kerja pariwisatadan masyarakat dalam memberi pelayanan kepada wisatawan yang akan dan sedang berkunjung. 


\section{Analisis SWOT}

Berdasarkan temuan dilapangan maka dapat dianalisis dengan menggunakan analisis SWOT untuk menjawab tujuan dan permasalahan penelitian yaitu :

Tabel 7

Matriks Analisis SWOT

\begin{tabular}{|c|c|c|}
\hline & Strength $(\mathrm{S})$ & Weakness (W) \\
\hline $\begin{array}{l}\text { Potensi } \\
\text { Wisata }\end{array}$ & $\begin{array}{l}\text { 1. memiliki } \\
\text { keragaman daya } \\
\text { tarikdan atraksi } \\
\text { dengan potensi } \\
\text { bahari dan } \\
\text { budaya yang } \\
\text { unik, alami dan } \\
\text { indah } \\
\text { 2. sifat } \\
\text { kekeluargaan, } \\
\text { kekerabatan dan } \\
\text { keterbukaan } \\
\text { masyarakat. } \\
\text { 3. tingakat } \\
\text { keamanan dan } \\
\text { kenyamanan } \\
\text { yang terjamin } \\
\text { 4. Harga } \\
\text { transportasi yang } \\
\text { terjangkau } \\
\text { 5. Adanya minat } \\
\text { dari masyarakat } \\
\text { untuk } \\
\text { pengembangan } \\
\text { kawasan } \\
6 . \text { kondisi } \\
\text { infrastruktur } \\
\text { jalan yang baik } \\
\text { menuju kawasan }\end{array}$ & $\begin{array}{l}\text { 1. fasilitas } \\
\text { yang kurang } \\
\text { memadai ( } \\
\text { penginapan, } \\
\text { rumah makan, } \\
\text { toko, fasilitas } \\
\text { kesehatan, } \\
\text { tempat parkir, } \\
\text { toilet, } \\
\text { promosi, } \\
\text { papan } \\
\text { petunjuk } \\
\text { lokasi) } \\
\text { 2. kondisi } \\
\text { infrastruktur } \\
\text { jalan dalam } \\
\text { kawasan yang } \\
\text { buruk } \\
\text { 3. minimnya } \\
\text { jumlah } \\
\text { transportasi } \\
\text { menuju } \\
\text { kawasan } \\
\text { 4.kurang } \\
\text { keamanan dan } \\
\text { kenyamanan } \\
\text { dalam } \\
\text { bertransportasi } \\
\text { menuju } \\
\text { kawasan. } \\
5 . \text { minimnya } \\
\text { jumlah biro } \\
\text { perjalanan }\end{array}$ \\
\hline $\begin{array}{l}\text { Opportunities } \\
\text { (O) }\end{array}$ & $\mathrm{SO}$ & WO \\
\hline $\begin{array}{l}\text { 1. wisatawan } \\
\text { mudah } \\
\text { mencapai } \\
\text { lokasi } \\
\text { 2.tingginya } \\
\text { potensi dan } \\
\text { minat } \\
\text { wisatawan } \\
\text { 3. jalur } \\
\text { penerbangan } \\
\text { dan pelayaran }\end{array}$ & $\begin{array}{l}\text { 1. } \\
\text { Mengembangkan } \\
\text { wisata minat, } \\
\text { khususnya } \\
\text { wisata diving \& } \\
\text { snorkeling, } \\
\text { mengembangkan } \\
\text { seni dan budaya } \\
\text { 2. Membangun } \\
\text { jaringan dengan } \\
\text { obyek-obyek lain } \\
\text { yang ada di }\end{array}$ & $\begin{array}{l}1 . \\
\text { Membangun } \\
\text { pusat } \\
\text { informasi } \\
\text { wisata untuk } \\
\text { mempermudah } \\
\text { wisatawan } \\
\text { dalam hal } \\
\text { informasi. } \\
2 . \\
\text { Meningkatkan }\end{array}$ \\
\hline
\end{tabular}




\begin{tabular}{|c|c|c|}
\hline $\begin{array}{l}\text { yang sudah } \\
\text { berkembang } \\
\text { 4. adanya } \\
\text { perhatian } \\
\text { pemerintah } \\
\text { pusat terhadap } \\
\text { kawasan } \\
\text { Indonesia } \\
\text { Timur } \\
5 . \\
\text { perkembangan } \\
\text { teknologi dan } \\
\text { informasi }\end{array}$ & $\begin{array}{l}\text { Indonesia, } \\
\text { khususnya } \\
\text { Ibukota Kupang } \\
\text { 3. Bekerjasama } \\
\text { dengan agen- } \\
\text { agen perjalanan } \\
\text { baik yang ada di } \\
\text { Indonesia } \\
\text { maupun luar } \\
\text { negeri. } \\
\text { 4. } \\
\text { Meningkatkan } \\
\text { kerjasama antara } \\
\text { pemerintah pusat } \\
\text { dan daerah. } \\
\text { 5. Membuat } \\
\text { website khusus } \\
\text { wisata Kawasan } \\
\text { Batu Termanu } \\
\text { dan Kabupaten } \\
\text { Rote Ndao. } \\
\text { 6. Lebih } \\
\text { mempermudah } \\
\text { akses masuk } \\
\text { kawasan wisata. }\end{array}$ & $\begin{array}{l}\text { sumberdaya } \\
\text { manusia. } \\
3 . \\
\text { Mendatangkan } \\
\text { investor. } \\
4 . \\
\text { Menyediakan } \\
\text { serta } \\
\text { melengkapi } \\
\text { infrastruktur } \\
\text { dan fasilitas } \\
\text { wisata guna } \\
\text { menunjang } \\
\text { aktivitas } \\
\text { wisatawan. }\end{array}$ \\
\hline Treats ( T ) & ST & WT \\
\hline $\begin{array}{l}\text { 1. kesadaran } \\
\text { sebagian } \\
\text { masyarakat } \\
\text { aakan } \\
\text { lingkungan } \\
\text { yang masih } \\
\text { kurang. } \\
\text { 2. interusi } \\
\text { budaya asing } \\
\text { ke } \\
\text { masyarakat. } \\
\text { 3. persaingan } \\
\text { dengan } \\
\text { kawasan } \\
\text { wisata yang } \\
\text { memiliki } \\
\text { ceruk pasar } \\
\text { yang sama }\end{array}$ & $\begin{array}{l}1 . \\
\text { Mempertahankan } \\
\text { keragaman \& } \\
\text { menambah } \\
\text { keragaman } \\
\text { atraksi. } \\
2 . \\
\text { Mempertahankan } \\
\text { image kawasan. } \\
\text { 3. } \\
\text { Meningkatkan } \\
\text { pemahaman } \\
\text { masyarakat akan } \\
\text { manfaat } \\
\text { ketahanan sosial } \\
\text { budaya }\end{array}$ & $\begin{array}{l}1 . \\
\text { Meningkatkan } \\
\text { kesadaran } \\
\text { masyarakat } \\
\text { akan } \\
\text { pentingnya } \\
\text { lingkungan \& } \\
\text { wisata } \\
\text { berkelanjutan. } \\
2 . \\
\text { Membangun } \\
\text { kerjasama } \\
\text { dengan } \\
\text { pemerintah } \\
\text { pusat untuk } \\
\text { memelihara } \\
\text { keamanan }\end{array}$ \\
\hline
\end{tabular}

\section{Penutup}

Kawasan Batu Termanu jika dilihat dari segi daya tarik site attractionnya maka sudah bisa dikatakan layak untuk adanya pengembangan. Tetapi dari segi event atraktsinya masih kurang karena jumlahnya sudah banyak tetapi frekuensi eventnya yang terlalu jarang. Dari segi fasilitas yang ada di Kawasan Batu Termanu baik dari jumlah dan kondisinya maka bisa dikatakan sangat kurang baik, mulai dari penginapannya, rumah makan, pertokoan, dan fasilitas pendukungnya. Infrastruktur penunjang sudah bisa dikatakan baik hanya saja kondisi jalan dalam Kawasan Batu Termanu yang masih buruk. Transportasi menuju Kawasan Batu Termanu sudah baik dari segi jumlah, frekuensinya yang kurang baik adalah keamanan dan dan kondisinya saja. Keramahtamahan yang ditawarkan Kawasan Batu Termanu sudah sangat baik dari segi keamanan, kenyamanan dan pelayanannya. Secara umum dapat disimpulkan bahwa potensi wisata di Kawasan Batu 
Termanu sudah cukup baik untuk di lakukan pengembangan selanjutnya. Disarankan bagi pihat-pihak terkait dalam pengembangan Kawasan Batu Termanu lebih berfokus pada meningkatkan fasilitas dan infrastruktur penunjang pariwisata dengan strategi yang tepat.

\section{Daftar Pustaka}

Antara, M. 2010. Metodologi Penelitian Pariwisata. Denpasar

Antari, Ni Putu Septhi. 2001. Pengembangan Kawasan Pura Sada sebagai Objek dan Daya Tarik Wisata di Desa Kapal Kecamatan Mengwi Kabupaten Bandung ( Laporan Akhir). Denpasar.

Atabuy, Frits. 2012. Strategi pengembangan kawasan Wisata Bahari Berbais masyarakat Kabupaten Rote Ndao.

Badan Pusat Statistik Propinsi Nusa Tenggara Timur. 2013. Propinsi Nusa Tenggara Timur dalam Angka.

Badan Pusat Statistik Kabupaten Rote Ndao.2013. Kabupaten Rote Ndao dalam Angka.

Cooper, C. John Fletcher, David Gilbert and Stephen Wanhill. 1995. Tourism : Principles and Practice. London: Pitman Publishing.

David, Fred R .2006. Manajemen Strategis. Edisi Sepuluh. Penerbit Salemba Empat. Jakarta

Dinas Pariwisata dan Kebudayaan Kabupaten Rote Ndao. 2013. Dokumen Laporan Tahunan. Ba'a 2005. Rencana Tata Ruang Kawasan Batu Termanu. Ba'a

Dowling G, 2003. Creating Corporate Reputations, Identity, Image and Performance.

Eoh. Jeni. 2013 , Masalah Pembangunan Nusa Tenggara Timur.

Lunberg E Donald. 1997 , Ekonomi Pariwisata, PT Gramedia Pustaka Utama, Jakarta,

Manafe A. H dan Tanaamah A R. 2001, Masyarakat Lokal dan Keberadaan Wisatawan di Nemberala: Jurnal Studi Pembangunan Interdisiplin. Denpasar

Pitana I Gede. 2009. Pengantar Ilmu Pariwisata. Penerbit Andy. Yogyakarta

Rangkuti, Freddy. 2006. Analisis SWOT Teknik Membedah Kasus Bisnis. PT. Gramedia Pustaka Utama, Jakarta

Suwantoro G. 2004. Dasar- dasar Pariwisata. Penerbit Andi. Yogyakarta

Swarbrooke,John. 2002. The Development and Managemaent of Visitor Attractions. Edisi Kedua

Spillane J James, 1994. Ekonomi Pariwisata Sejarah dan Prospeknya. Penerbit Kanisius.

Umar, H. 2000. Metode Penelitian untuk Skripsi dan Tesis Bisnis, Cet. Ketiga. Penerbit PT. Raja Grafindo Persada, Jakarta.

Undang - Undang Republik Indonesia Nomor 9 Tahun 1990, Undang - Undang Kepariwisataan.

Villers J David. 1999, dalam Anom I Putu. 2013. Potensi Kepariwisatan propinsi NTT (Studi kasus di Kawasan Pariwisata Komodo). Denpasar

Wisaya .1997 dalam http://wiranata-wira.blogspot.com/2009/12/pariwisata-menurut-para-ahli.html 
Wahab, Salah. 1999. Manajemen Kepariwisataan, Jakarta.

Yoeti, Oka A 2008. Ekonomi Pariwisata .Yogyakarta

2008. Perencanan dan Pengembangan Pariwisata. Pradnya Paramita. Jakarta

Zoh Z Andre dan Indarayana.N.D.K Maria.2008. Rote Ndao Mutiara dari Selatan. Jakarta

https://www.google.co.id/?hl=en\&gws_rd=ssl\#hl=en-ID\&q=website+resmi+propinsi+ntt

https://www.google.co.id/?hl=en\&gws rd=ssl\#hl=en-Iq=website+resmi+kabupaten+rotendao 